\title{
Arterial stenting with self-expandable and balloon-expandable endoprostheses
}

\author{
Willem J. van der Giessen, Patrick W. Serruys, Leon J. van Woerkens, Kevin J. Beatt, Willem J. Visser ${ }^{1}$, \\ Johannes F. Jongkind ${ }^{1}$, Robert H. van Bremen, Erik Ridderhof ${ }^{2}$, Heleen van Loon, Loe Kie Soei, \\ Heleen M.M. van Beusekom \& Pieter D. Verdouw \\ The Department of Cardiology, Thoraxcenter, ${ }^{1}$ the Department of Cellbiology, and \\ ${ }^{2}$ the Laboratory for Experimental Surgery, Erasmus University Rotterdam, Rotterdam, The Netherlands
}

Key words: arteries, coronary, grafts, pigs, prosthesis

\section{Summary}

Coronary angioplasty is complicated by acute occlusion (within 24 hours) and late restenosis (within 6 months) in $2-5 \%$ and $20-40 \%$ of the cases, respectively. Vascular endoprostheses (stents) may provide the cardiologist with a solution to some of these complications. Several stent-devices are now available for experimental and clinical evaluation. In this study we describe our experience with two metallic stents in normal arteries of swine.

Self-expandable, stainless steel stents $(3.5 \mathrm{~mm}$ diameter) were implanted in 17 peripheral arteries, eight of which were deendothelialized by prior balloon angioplasty. Following implantation, the animals received antithrombotic therapy with acenocoumarol and aspirin ( 8 stents), or aspirin alone ( 9 stents). After 1 week repeat angiography was performed, which showed patency of all stented arteries. Microscopy showed complete covering by neointima, $80 \mu \mathrm{m}$ in thickness. This self-expandable stent (SES) and a balloonexpandable stent (BES), constructed of tantalum, were implanted in normal coronary arteries. SES (3.0 and $3.5 \mathrm{~mm}$ ) receiving animals were treated with coumadines (10 stents) or received no antithrombotic treatment (16 stents) after implantation. BES receiving animals were also not treated (10 stents). Three untreated animals with SES died suddenly within 48 hours. Postmortem examination showed partial or complete thrombosis of all six stents in these animals, resulting in a patency rate of $62 \%$ after 1 week. All animals with SES, which were treated with coumadines, and all animals with BES (untreated) had patent stents after one week. It is concluded that SES implanted in normal coronary arteries of pigs, which do not receive additional antithrombotic treatment, show a $38 \%$ occlusion rate within 48 hours, but show $100 \%$ patency after 1 week, when the animals are treated with coumadines. BES implanted in normal coronary arteries of pigs, which do not receive antithrombotic drugs, are $100 \%$ patent after 1 week.

\section{Introduction}

The application of percutaneous transluminal coronary angioplasty (PTCA) for the treatment of atherosclerotic coronary artery disease has increased considerably in recent years. The initial success rate is high $[1,2]$, with an incidence of acute or subacute occlusion at the site of angioplasty of $2-5 \%[3,4]$. Restenosis several months after the procedure occurs frequently with an incidence of $20-40 \%$ [5-7]. The effect of pharmacological therapy on acute complications [8-11] and late restenosis [12] is still unclear. The implantation of vascular endoprostheses was already attempted in the early 
days of angioplasty for the treatment of procedurerelated complications and the prevention of restenosis [13]. Narrowing of the stented segment caused by neointimal hyperplasia limited the use of these devices. Changes in design, the use of other metal alloys, and miniaturization of the endoprostheses has resulted in the availability of several types of stents for experimental and clinical evaluation [14-17]. Early experimental and clinical experience, however, indicates that the thrombogenic nature of most devices remains a concern [18, 191. We therefore studied the short-term angiographic patency of two different stents in pigs, treated with different antithrombotic regimen.

\section{Materials and methods}

\section{Description of the stents}

\section{Self-expandable stent (SES)}

The SES used (Wallstent $\left.{ }^{(}\right)$Medinvent SA, Lausanne, Switzerland) is a stainless steel, open-weave wire mesh. The wires are $80 \mu \mathrm{m}$ in thickness. The elastic properties of this prosthesis are such that its diameter can be substantially reduced by elongation. It can thus be constrained on a small-diameter delivery-catheter (diameter catheter plus stent is approximately $1.6 \mathrm{~mm}$ ), which consists of two coaxial catheters. The proximal regions of the two coaxial catheters are joined by an invaginated rolling membrane, which effectively retains the prosthesis. Withdrawal of the outer catheter rolls back the membrane progressively, thus releasing the stent, which tends to return to its original diameter, thereby anchoring itself against the arterial wall. The unconstrained diameters of the stents used in this study were 3.0 and $3.5 \mathrm{~mm}$, with a length of 15 to $19 \mathrm{~mm}$.

\section{Balloon-expandable stent (BES)}

The BES used (Wiktor ${ }^{\circledR}$, Medtronic Inc., Minneapolis, USA) is constructed of a single tantalum wire, which is coiled in interdigitating loops. This prosthesis is crimped onto the balloon of a standard angioplasty catheter. The features of this prosthesis design are such that by inflating the balloon the diameter of the stent increases without altering its length. The maximal diameter of the balloon after inflation determines the ultimate diameter of the prosthesis after implantation. One inflation at $8 \mathrm{Atm}$ is sufficient to open the stent and allows the safe withdrawal of the deflated balloon. The balloon-diameters of the mounted angioplasty catheters used in this study were 3.0 and $3.5 \mathrm{~mm}$, and the lengths of the prostheses $14-16 \mathrm{~mm}$.

\section{Application of the stents}

Peripheral implantations of self-expandable stents After an overnight fast 6 Yorkshire swine (18$25 \mathrm{~kg}$ ) were sedated with $20 \mathrm{mg} \cdot \mathrm{kg}^{-1}$ ketamine hydrochloride. Following endotracheal intubation the animals were connected to a respirator for artificial ventilation with a mixture of oxygen and nitrous oxide $(1: 2)$. Anaesthesia was maintained with $1-4$ vol\% enflurane, while pancuronium bromide was used as a muscle relaxant. An $8 \mathrm{~F}$ introduction sheath was placed via the left carotid artery in the descending aorta. After intravenous administration of 5,000 IU heparin and $100 \mathrm{mg}$ aspirin, an $8 F$ guiding catheter was advanced to the aorto-iliac bifurcation. After baseline angiography of both femoral arteries an angioplasty balloon catheter (balloon size $3.5 \mathrm{~mm}$ ) was advanced over a long guidewire in the left femoral artery. From the angiograms, and using the diameter of the guiding catheter as a reference, a segment of the left femoral artery was chosen with a diameter of $3.0 \mathrm{~mm}$.

Table 1. Diameters and numbers of self-expandable ('Wallstent') and balloon-expandable ('Wiktor') stents implanted in peripheral and coronary arteries of pigs. $\mathrm{RCA}=$ right coronary artery; $\mathrm{LAD}=$ left anterior descending coronary artery; LCX $=$ left circumflex coronary artery.

\begin{tabular}{llrl}
\hline stent type & stent diameter & $\mathrm{n}$ & artery \\
\hline 'Wallstent' & $3.5 \mathrm{~mm}$ & 9 & right femoral \\
& $3.5 \mathrm{~mm}$ & 8 & left femoral \\
'Wallstent' & $3.0 \mathrm{~mm}$ & 13 & RCA 3, LAD 6, LCX 4 \\
& $3.5 \mathrm{~mm}$ & 13 & RCA 5, LAD 4, LCX 4 \\
'Wiktor' & $3.0 \mathrm{~mm}$ & 6 & LAD 4, LCX 2 \\
& $3.5 \mathrm{~mm}$ & 4 & RCA 2, LCX 2
\end{tabular}




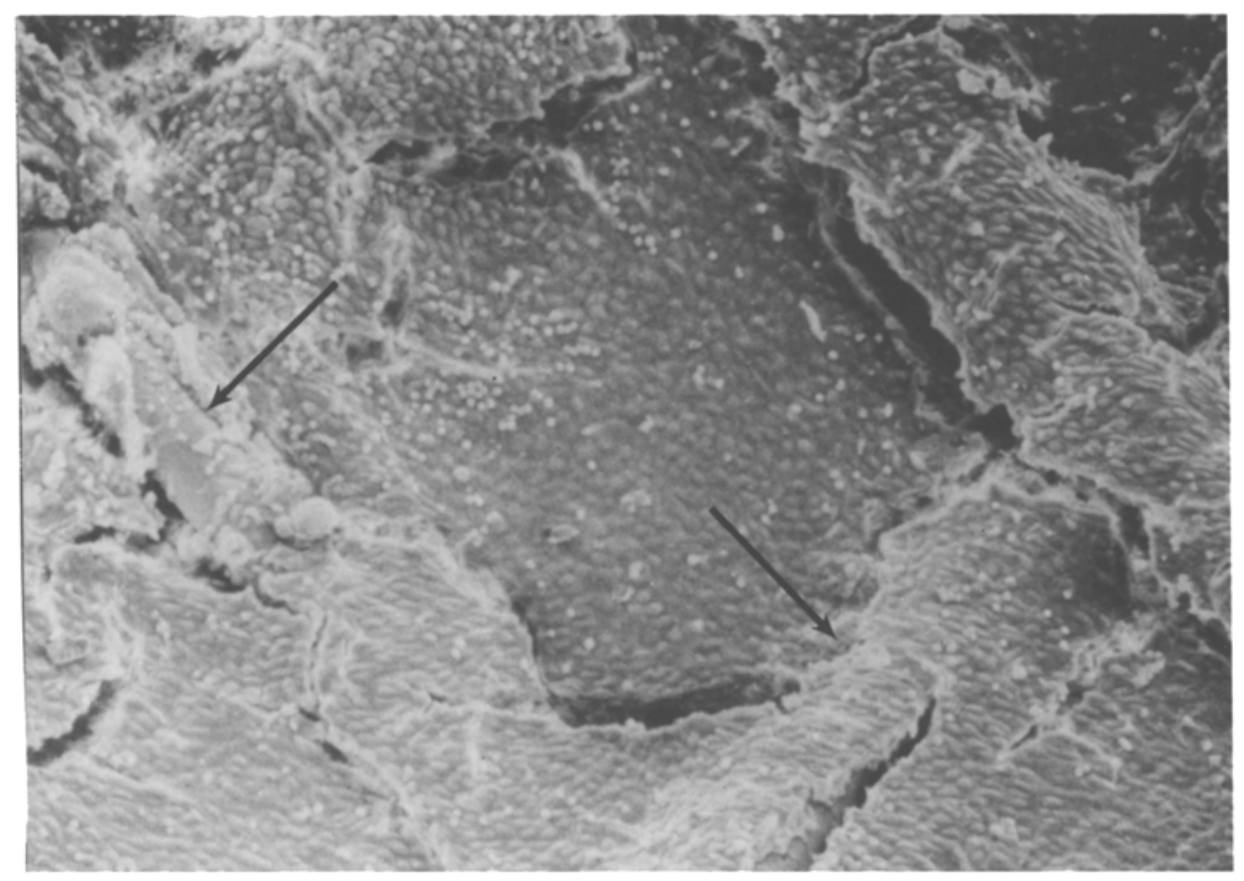

Fig. 1. Scanning electron microscopical picture (magnification $1,250 \times$ ) of porcine femoral arterial segment 7 days after implantation of a SES. The wires (arrow) are covered with a continuous layer of spindle shaped endothelial cells. Fissures in the endothelial layer are caused by the preparation of the specimen.

At that point the angioplasty balloon was inflated twice for $60 \mathrm{~s}$. at $10 \mathrm{Atm}$ inflation pressure. Thereafter the angioplasty catheter was withdrawn, and angiography was repeated. A SES (unconstrained diameter $3.5 \mathrm{~mm}$ ) mounted on the tip of the delivery catheter was positioned over the long guidewire at the dilated arterial segment. After the stent was released repeat angiography was performed. The same procedure was followed for placement of a stent in the right (contralateral) femoral artery, except for the fact that angioplasty was not per- formed at this side. The catheters were removed, and the animals were allowed to recover from anaesthesia. After 6-10 days the animals were again anaesthetized and angiography of the stentrelated arteries was performed. Immediately thereafter, the stent-containing arterial segments were perfused in vivo with saline (perfusion pressure $75 \mathrm{mmHg}$ ), removed and placed in buffered glutaraldehyde until preparation for microscopy. Thereafter the animals were sacrificed with an overdose of pentobarbitone sodium.

Table 2. Angiographic patency one week after implantation of stents in peripheral and coronary arteries of pigs, which received different antithrombotic treatment. ASA = acetylsalicylic acid; $F / U=$ follow up.

\begin{tabular}{llllc}
\hline stent type & treatment & $\mathrm{n}$ & F/U (days) & patency (\%) \\
\hline 'Wallstent' & ASA/coumadines & 9 & 6 & 100 \\
(peripheral) & ASA & 8 & $8-10$ & 100 \\
'Wallstent' & - & 16 & 7 & 62.5 \\
(coronary) & coumadines & 10 & 7 & 100 \\
'Wiktor' & - & 10 & 7 & 100 \\
(coronary) & & & & \\
\hline
\end{tabular}




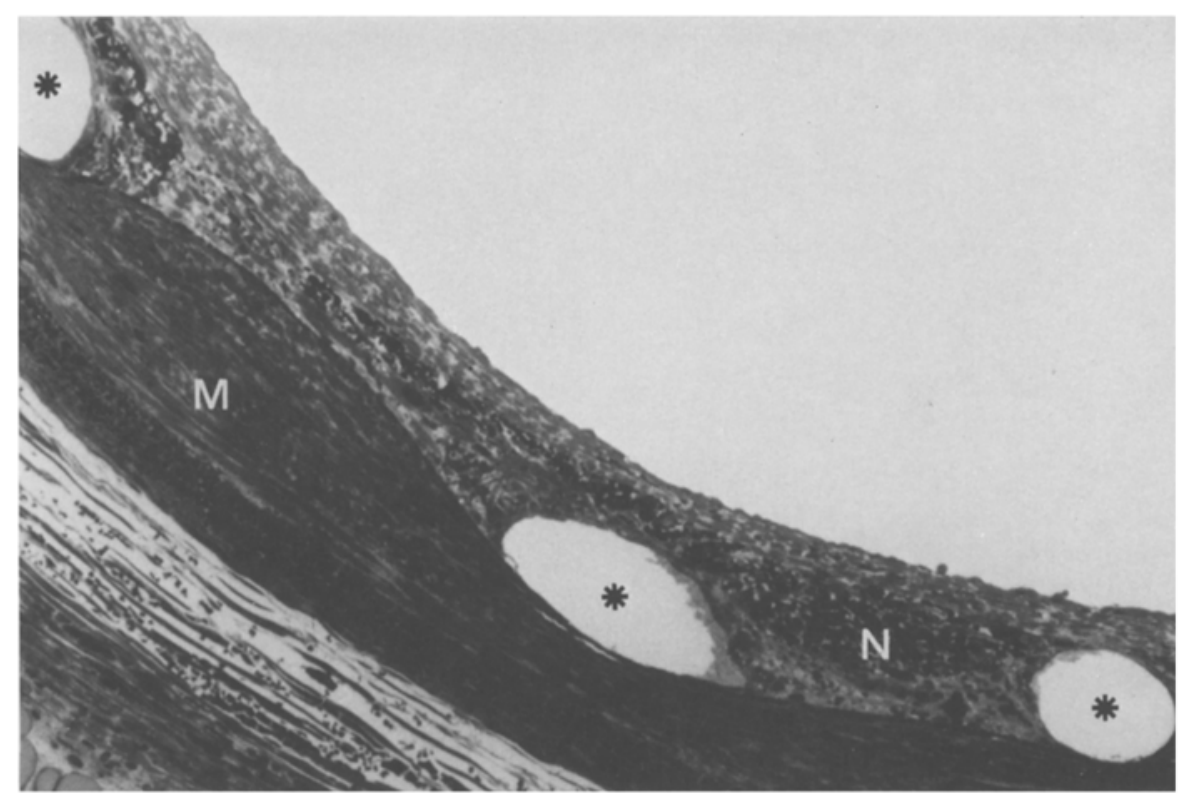

Fig. 2. Light microscopy of a porcine femoral artery 8 days after implantation of a SES (magnification $200 \times$ ). The voids (asterisk) formerly occupied by the stent wires exert pressure to the media muscularis $(\mathrm{M})$, and are covered by neointima (N).

\section{Antithrombotic treatment after femoral implantation of self-expandable stents}

Starting the day of the procedure two animals (8 stents) received daily calciparin $25,000 \mathrm{IU}$ subcutaneously until oral acenocoumarol had prolonged the prothrombin time threefold. Aspirin $100 \mathrm{mg}$. $24 \mathrm{~h}^{-1}$ intravenously was also added. The other four animals ( 9 stents) received only $100 \mathrm{mg}$ of aspirin in one daily oral dose.

\section{Coronary implantations with self-expandable stents}

After an overnight fast 13 Yorkshire swine (40$46 \mathrm{~kg}$ ) were sedated with $20 \mathrm{mg} \cdot \mathrm{kg}^{-1}$ ketamine hydrochloride. Following endotracheal intubation, mechanical ventilation and anaesthesia as described above, a 9F sheath was placed via the left carotid artery in the ascending aorta. After intraarterial administration of $5.000 \mathrm{IU}$ heparin, baseline coronary angiography was performed using an $8 \mathrm{~F}$ guiding catheter. Using the diameter of the guiding catheter as a reference, two coronary segments with a diameter of approximately 2.5 and/or $3.0 \mathrm{~mm}$ were chosen from the angiograms from two of the three major coronary arteries (left anterior descending coronary artery: LADCA; left circumflex coronary artery: LCXCA; right coronary artery: RCA). A SES, constrained on the delivery catheter, was advanced over a long guidewire and positioned in one of the two selected coronary segments. After the stent was released, angiography was repeated to confirm its proper placement. The second stent was released in the other coronary segment. Stents with an unconstrained diameter of $3.0 \mathrm{~mm}$ were placed in coronary segments with a measured diameter of $2.5 \mathrm{~mm}$, and those with an unconstrained diameter of $3.5 \mathrm{~mm}$ in $3.0 \mathrm{~mm}$ vessels. The number of stents, diameters and selected coronary arteries are summarized in Table 1.

After 7 days the animals were again anaesthetized and angiography of the stent-containing coronary arteries was performed.

\section{Antithrombotic treatment after coronary implantation of self-expandable stents} Eight animals (16 stents) received no antithrombotic treatment after implantation. During one 
week the other five animals (10 stents) received acenocoumarol, in a dose that lowered the Quicktest to less than $10 \%$ of normal, starting the day before the procedure.

\section{Coronary implantations with balloon-expandable} stents

After an overnight fast 5 Yorkshire swine (41$48 \mathrm{~kg}$ ) were anaesthetized as described above. A 9F sheath was placed via the left carotid artery in the ascending aorta. After intraarterial administration of 5,000 IU of heparin, baseline coronary angiography was performed using an $8 \mathrm{~F}$ guiding catheter. From these angiograms two coronary sites in two of the tree major coronary branches (LADCA; LCXCA; RCA) were chosen as described for the SES. Thereafter, a BES was placed at both sites as follows: the catheter with the stent crimped onto its balloon was positioned at a desired position, and the balloon was inflated for $30 \mathrm{~s}$ with an inflation pressure of $8 \mathrm{Atm}$. Stents mounted on a $3.0 \mathrm{~mm}$ balloon were placed in vessels with an approximate diameter of $2.5 \mathrm{~mm}$, and stents mounted on a $3.5 \mathrm{~mm}$ balloon were implanted in vessels with a diameter of $3.0 \mathrm{~mm}$. Stent diameters, numbers and selected coronary vessels are summarized in Table 1.

After 7 days the animals underwent repeat angiography under anaesthesia. Thereafter the thorax was opened by a midsternal split. The ascending aorta was cross clamped and $500 \mathrm{ml}$ of saline, followed by $400 \mathrm{ml}$ of a phosphate buffered mixture of $1 \%$ glutaraldehyde and $4 \%$ formaldehyde, was infused in the aortic root immediately above the coronary ostia at a pressure of $120 \mathrm{mmHg}$. The heart was excised, the coronary arteries dissected out, and placed in $4 \%$ formaldehyde and $1 \%$ glutaraldehyde in phosphate buffer ( $\mathrm{pH} 7.3$ ) for at least 48 hours until preparation for microscopy.

\section{Antithrombotic treatment after coronary implantation of balloon-expandable stents}

Antithrombotic drugs were not administered after the implantation of the BES.

\section{Microscopical examination}

After fixation, the stent-containing arterial seg-

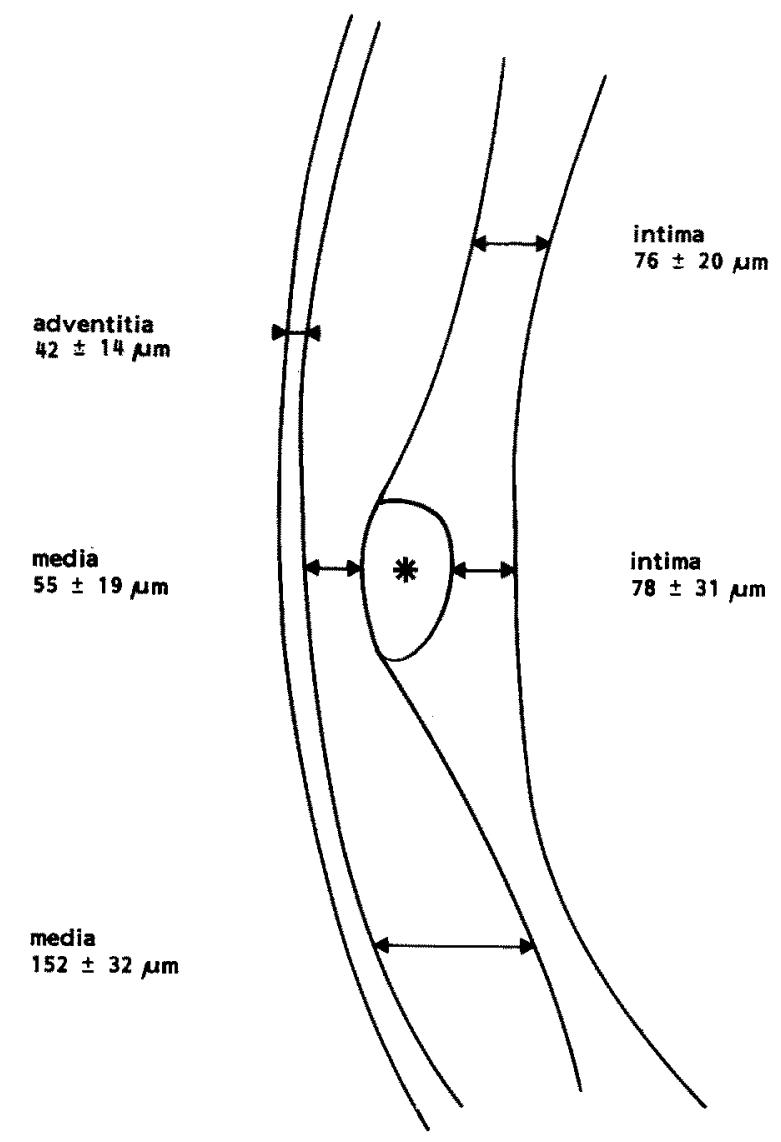

Fig. 3. Schematic drawing of a section of a stented porcine artery (e.g. as in Fig. 2). The average values of the measurements of the layers of 4 porcine femoral arteries 6-10 days after placement of a SES are included.

ments were divided lengthwise into two equal parts using a pair of fine scissors. From one half of each vessel the stent wires were removed. Both halves were washed in $0.1 \mathrm{M}$ cacodylate buffer ( $\mathrm{pH} 7.3$ ), postfixed in $1 \%$ osmium tetroxide and washed overnight in $0.1 \mathrm{M}$ cacodylate. The specimen were placed in $1 \%$ tannic acid for $60 \mathrm{~min}, 1 \% \mathrm{Na}_{2} \mathrm{SO}_{4}$ for $10 \mathrm{~min}$ and again washed in $0.1 \mathrm{M}$ cacodylate buffer. The half of the vessel containing the stent wires underwent dehydration in graded ethanol and critical point drying with liquid $\mathrm{CO}_{2}$. This part of each vessel was mounted on a specimen table and sputtercoated with gold before examination in a scanning electron microscope (ISI-DS-130). The other half was dehydrated in graded aceton and embedded in Epon. After sectioning and staining trans- 


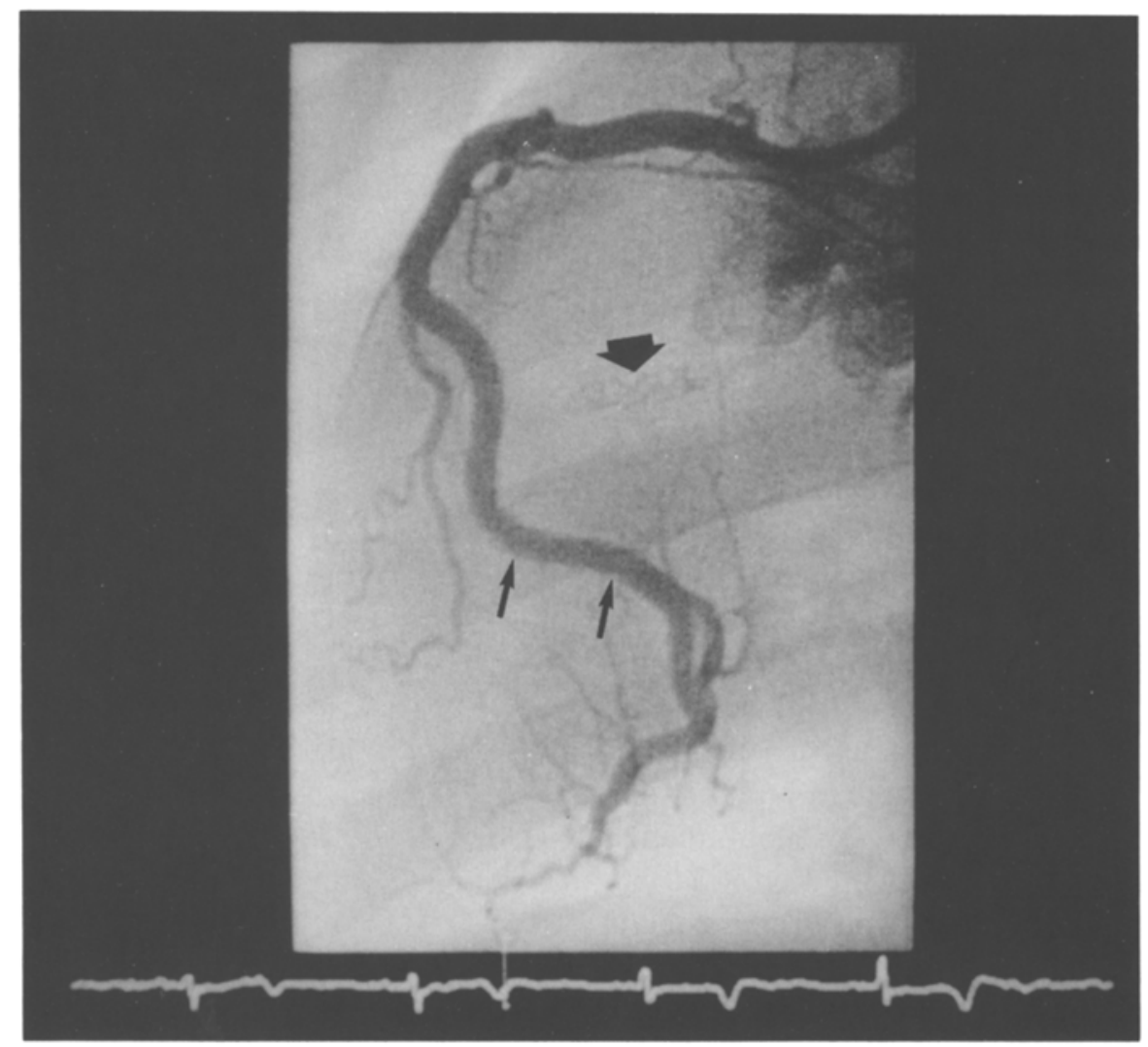

Fig. 4. Angiogram of the right coronary artery of a pig 7 days after implantation of a BES. The fine arrows indicate the stented coronary segment, which appears patent without narrowing of the lumen. The solid arrow marks a clearly visible stent in the LADCA.

mission microscopy was performed using a Zeiss light microscope and a Philips EM 400 electron microscope.

\section{Results}

\section{Peripheral implantations of self-expandable stents}

One femoral artery (6\%) showed complete occlusion after balloon-denudation, and could not be reopened by the intraarterial administration of isosorbide dinitrate. As a result, 9 stents were placed in right femoral arteries (without angioplasty) and 8 stents in left femoral arteries (after angioplasty). After 6-10 days all stent-containing arteries were angiographically patent, without signs of stenosis or intraluminal defects (Table 2). This means that all stents were patent, irrespective of earlier endothelial damage or the addition of coumadines to aspirin. Scanning electron microscopy showed that all stents were covered by an endothelial lining as early as 6 days after implantation (Fig. 1). Transmission microscopy showed that the stent wires were incorporated in the arterial wall and covered by a neointima (Fig. 2). Measurement of the arterial layers showed that the media was considerably compressed at the site of the wires (Fig. 3). Median thickness of the neointima on top of or between the wires was $80 \mu \mathrm{m}$ (range $50-125 \mu \mathrm{m}$ ).

\section{Coronary implantation of self-expandable stents}

Three of the 8 animals ( 6 stents) which did not receive additional anticoagulant treatment, died 
suddenly within 48 hours after implantation. Postmortem examination showed partial or complete thrombotic occlusion within all 6 stents. The other 5 animals in this group survived, and repeat angiography after 1 week revealed normal patency of all 10 stented coronary arteries in these animals (Table 2). All 5 animals ( 10 stents), which received antithrombotic prophylaxis with coumadines survived. Repeat angiography in this group after 1 week revealed normal patency of all stented coronary segments.

\section{Coronary implantations of balloon-expandable stents}

All 5 animals, which received a total number of 10 BES, survived for one week. Repeat angiography at this time showed normal patency of all stented coronary arteries, without signs of intraluminal defects (Table 2; Fig. 4).

Scanning electron microscopy revealed that the stent wires were completely covered by normal appearing endothelium after 1 week (Fig. 5). Furthermore, the luminal surface of the arteries showed corrugation between the stent wires. Transmission microscopy of the stented segments confirmed the incorporation of the stent in the wall of the coronary arteries, and considerable compression of the arterial media.

\section{Discussion}

Metallic vascular endoprostheses are currently under investigation in the coronary arterial tree of experimental animals and man. The most important limitations of its widespread use in clinical practice are thrombogenicity and restenosis in the stent due to neointimal hyperplasia. The most promising clinical indications seem to be implantations in stenosed aortocoronary venous bypass grafts or when used as a 'bail-out'-device for acute occlusion after angioplasty [20-22]. Turbulent flow, exposure of the subendothelium and accumulation of prothrombotic factors require, however, that a stent-device is athrombogenic. Stainless steel

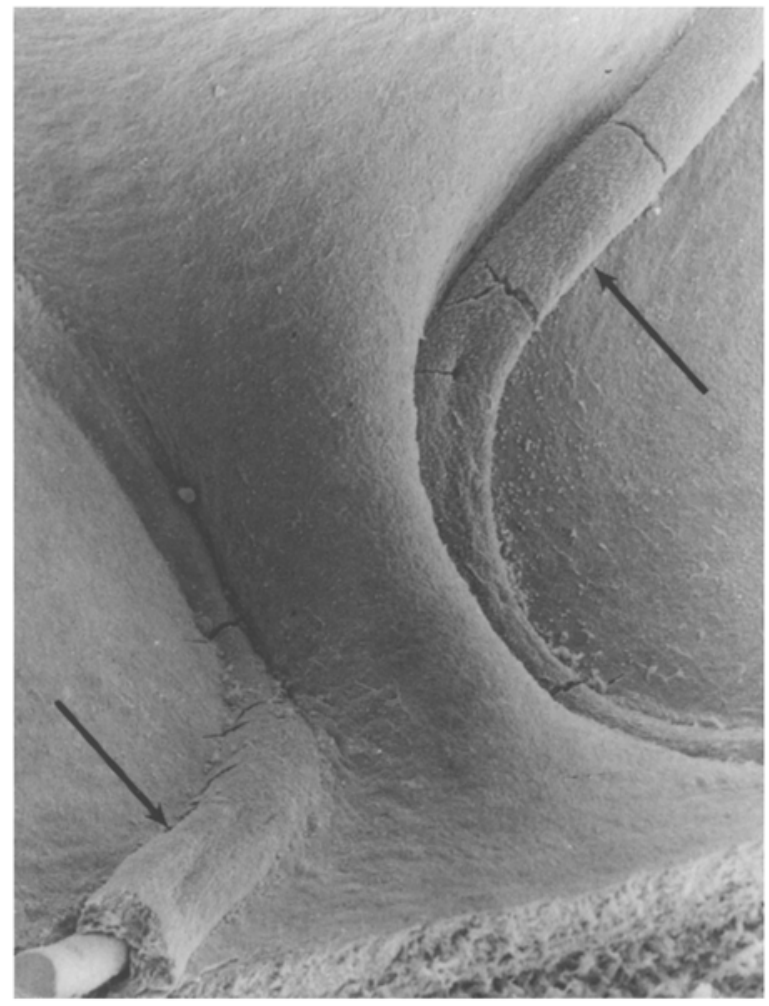

Fig. 5. Scanning electron micrograph (magnification $75 \times$ ) of a segment of a left circumflex coronary artery 7 days after implantation of a BES. The stent wire (arrows) is completely covered with an endothelial lining.

is not the material of choice for use in such a situation. Physicochemical and biological surface modification of the stent-wires may provide a solution [23, 24], but up till now these attempts have not been fruitful.

Stent implantation in the native coronary circulation immediately after angioplasty for the prevention or treatment of restenosis seems less promising than originally envisaged [15]. Although the stent improves the immediate post-dilatation result [25-27], restenosis within the stented segment occurs frequently $[20,28,29]$. The present study describes for the first time an attempt to compare two stent-devices in the same animal model and in the same laboratory. Results suggest that the stainless steel self-expandable stent may be more thrombogenic than the tantalum balloon-expandable stent. As both devices are covered by endothelium within 
7 days, the need for additional antithrombotic treatment may be of short duration. However caution is required when interpreting the results of the present study. Apart from the metallic composition and the mode of delivery to the coronary arterial tree, many other variables are present between the devices. For instance the significance of wire thickness, density of the mesh or loops, and active or passive radial force after placement are not known.

\section{Acknowledgements}

The authors wish to thank Mrs Marjo van Ee for her secretarial assistance in the preparation of this manuscript, and Mr. B. Klazema (General Electric Plastics, Bergen op Zoom) for the use of the scanning microscope. This project is supported by the Netherlands Heart Foundation under grant no. NHS 88.077.

\section{References}

1. Anderson HV, Roubin GS, Leimgruber PP, Douglas IS, King SB, Grüntzig AR.. Primary angiographic success rates of percutaneous transluminally angioplasty. Am J Cardiol 1985; 56: 712-717.

2. Myler RK, Topol EJ, Shaw RE, Stertzer SH, Clark DA, Fishman J, Murphy MC. Multiple vessel coronary angioplasty: classification, results and patterns of restenosis in 494 consecutive patients. Cath Cardiovasc Diag 1987; 13: 1-15.

3. Bredlau CE, Roubin GS, Leimgruber PP, Douglas JS, King SB, Grüntzig AR. In-hospital morbidity and mortality in patients undergoing elective coronary angioplasty. Circulation 1985; 72: 1044-1052.

4. Simpfendorfer C, Belardi J, Bellamy G, Galan K, Franco I, Hollman J. Frequencies, management and follow-up of patients with acute coronary occlusion after percutaneous transluminal angioplasty. Am J Cardiol 1987; 59: 267-269.

5. Grüntzig AR, King SB, Schlumpf $M$, Siegenthaler W. Long-term follow-up after percutaneous transluminal coronary angioplasty. N Eng J Med 1987; 316: 1127-1132.

6. Meier B, King SB, Grüntzig AR, Douglas JS, Hollman J, Ischinger T, Galan K, Tankersley R. Repeat coronary angioplasty. J Am Coll Cardiol 1984; 4: 463-466.

7. Serruys PW, Luyten HE, Beatt KJ, Geuskens R, Feyter PJ de, Brand $M$ van den, Reiber JHC, Katen HJ ten, Es GA van, Hugenholtz PG. Incidence of restenosis after success- ful coronary angioplasty: a time-related phenomenon. Circulation $1988 ; 77$ : 361-371.

8. Bourassa MG, Schwartz L, David PR, Aldridge H, Lespérance $J$, Bonan $R$, Henderson $M$, Salvatori V. The role of antiplatelet agents in reducing periprocedural coronary angioplasty (PTCA) complications (abstract). J Am Coll Cardiol 1988; 11: $238 \mathrm{~A}$.

9. Pow TK, Varricchione TR, Jacobs AK, Ruocco NA, Ryan TJ, Christelis EM, Faxon DP. Does pretreatment with heparin prevent abrupt closure following PTCA (abstract)? J Am Coll Cardiol 1988; 11: 238 A.

10. Mufson L, Black A, Roubin G, Wilentz J, Mead S, McFarland K, Weintraub W, Douglas JS, King SB. A randomized trial of aspirin in PTCA: effect of high vs low dose aspirin on major complications and restenosis (abstract). J Am Coll Cardiol 1988; 11: $236 \mathrm{~A}$.

11. Lembo NJ, Black AJ, Roubin GS, Mufson LH, Wilentz JR, Douglas JS, King SB. Does the addition of dipyridamole to aspirin decrease acute coronary angioplasty complications? The results of a prospective randomized clinical trial (abstract). J Am Coll Cardiol 1988; 11:237 A.

12. Blackshear JL, O'Callaghan WG, Califf RM. Medical approaches to prevention of restenosis after coronary angioplasty. J Am Coll Cardiol 1987; 9: 834-848.

13. Dotter CT. Transluminally placed coil springs and arterial tube grafts: Long-term patency in the canine popliteal artery. Invest Radiol 1969; 4: 329-332.

14. Rollins N, Wright $\mathrm{KC}$, Charn sangavej $\mathrm{C}$, Wallace $\mathrm{S}$, Gianturco $\mathrm{C}$. Self-expanding metallic stents: preliminary evaluation in an atherosclerotic model. Radiology 1987; 163: 739-742.

15. Sigwart U, Puel J, Mirkovitch V, Joffre E, Kappenberger L. Intravascular stents to prevent occlusion and restenosis after transluminal angioplasty. $\mathrm{N}$ Eng J Med 1987; 316: $701-706$.

16. Schatz RA, Palmaz JC, Tio FC, Garcia F, Garcia O, Reuter SR. Balloon-expandable intracoronary stents in the adult dog. Circulation 1987; 76: 450-457.

17. Roubin GS, Robinson KA, King SB, Gianturco C, Black AJ, Brown JE, Siegel RJ, Douglas JS. Early and late results of intracoronary arterial stenting after coronary angioplasty in dogs. Circulation 1987; 76: 891-897.

18. Rousseau H, Puel J, Joffre F, Sigwart U, Dubouchier C, Imbert C, Knight C, Kropf L, Wallsten H. Self-expanding endovascular prosthesis: An experimental study. Radiology $1987 ; 164: 709-714$.

19. Schatz RA, Palmaz JC, Penn IM, Levine SL. Balloon expandable intravascular stents (BEIS) in human coronary arteries: a follow-up report (abstract). I Am Coll Cardiol 1989; 13: $106 \mathrm{~A}$.

20. King SB. Vascular stents and atherosclerosis. Circulation 1989; 79: 460-462.

21. Urban $P$, Sigwart $U$, Golf $S$, Kaufmann U, Sadeghi $H$, Kappenberger L. Intravascular stenting for stenosis of aortocoronary venous bypass grafts. J Am Coll Cardiol 1989; 13: 1085-1091. 
22. Serruys PW, Beatt KJ, Feyter PJ de, Suryapranata H, Brand M van den, Geuskens R. Stent implantation for the treatment of coronary artery bypass graft stenosis (abstract). J Am Coll Cardiol 1989; 13: $107 \mathrm{~A}$.

23. Hoffman AS. Modification of material surfaces to affect how they interact with blood. Ann N Y Acad Sci 1987; 516: 96-101.

24. Giessen WJ van der, Serruys PW, Visser WJ, Verdouw PD, Schalkwijk WP van, Jongkind JF. Endothelialization of intravascular stents. J Interven Cardiol 1988; 1: 109-120.

25. Serruys PW, Juillière Y, Bertrand ME, Puel J, Rickards AF, Sigwart U. Additional improvement of stenosis geometry in human coronary arteries by stenting after balloon dilatation. Am J Cardiol 1988; 61: G 71-76.

26. Puel J, Juillière Y, Bertrand ME, Rickards AF, Sigwart U, Serruys PW. Early and late assessment of stenosis geometry after coronary arterial stenting. Am J Cardiol 1988; 61: 546-553.

27. Beatt KJ, Bertrand M, Puel J, Rickards T, Serruys PW,
Sigwart U. Additional improvement in vessel lumen in the first 24 hours after stent implantation due to radial dilating force (abstract). J Am Coll Cardiol 1989; 13: 224 A.

28. Urban P, Sigwart U, Kaufmann U, Kappenberger L. Restenosis within coronary stents: possible effect of previous angioplasty (abstract). J Am Coll Cardiol 1989; 13: 107 A.

29. Litvack $F$. Intravascular stenting for prevention of restenosis: in search of the magic bullit. J Am Coll Cardiol; 13: 1092-1093.

Address for offprints:

W.J. van der Giessen,

Laboratory for Experimental Cardiology,

Thoraxcenter,

Erasmus University Rotterdam,

P.O. Box 1738,

3000 DR Rotterdam,

The Netherlands 